\title{
EVALUATION OF EFFECTIVE LOCATION OF PENDULUM TUNNED MASS DAMPERS FOR BUILDING WITH MASS IRREGULARITY
}

\author{
Prasad Sanjay Kulkarni ${ }^{1}$, R. S. Talikoti ${ }^{2}$ \\ ${ }^{I}$ P. G. Final Year student, Department of Civil Engineering, Sapkal Knowledge Hub, Nashik, Maharashtra, India \\ ${ }^{2}$ Professor and Head, Department of Civil Engineering, Sapkal Knowledge Hub, Nashik, Maharashtra, India
}

\begin{abstract}
The building may have the stiffness irregularity due to some unavoidable circumstances. While doing the seismic retrofitting of such buildings the location of dampers plays a vital role. The stiffness irregularity may be categorized as vertical or horizontal. The stiffness irregularity may rise due to unsymmetrical location of shear wall or similar stiff element, such irregularity is called as irregularity in plan. The dampers can be located towards the stiffened side of building or may be located away from the stiffened side. In this paper a G+20 building frame having stiffness irregularity in plan is selected and it seismic resistance is evaluated for three different location of PTMD. The mass ratio of was kept equal to 0.03. The Nonlinear modal time history analysis was performed using finite element software SAP. The performance parameters such as displacement, storey drift and maximum forces are compared and presented. The pendulum damper is modeled using nonlinear link element. The results indicates that along the axis where the building is symmetrical in plan the location away from the stiff element proves to be efficient location where as in other direction the damper located at centroid of building is more efficient.
\end{abstract}

Keywords: Stiffness Irregularity, Location of PTMD, Time History Analysis, SAP

\section{INTRODUCTION}

Now a day's most of the buildings are constructed with some of kind of irregularity. There are various types of irregularities related to stiffness and mass of the structure. The stiffness irregularity may arise due to unsymmetrical location of shear wall in the building, if building is situated on sloping ground, etc. In some cases the stiffness irregularity in plan may arise due to unsymmetrical location of water tank at roof of the building. The passive energy dissipation devices are one of the widely used devices for earthquake resistance. The application of pendulum tuned mass damper for buildings having irregularity needs to be evaluated in view of their location. The location of pendulum tuned mass damper is a key aspect in design of damper and considered to be an important factor as far as their design and application is concern.

\section{METHODOLOGY}

In the present paper a $\mathrm{G}+20$ building frame having stiffness irregularity in plan is considered for study. Four different models are created as follows

Model CM: Building with stiffness irregularity without any tunned mass damper. This model will act as a control model for study

Model M1: Building having stiffness irregularity with pendulum tunned mass damper located at the centroid of building.

Model M2: Building having stiffness irregularity with pendulum tunned mass damper located towards the shear wall
Model M3: Building having stiffness irregularity with pendulum tunned mass damper located towards other side of shear wall.

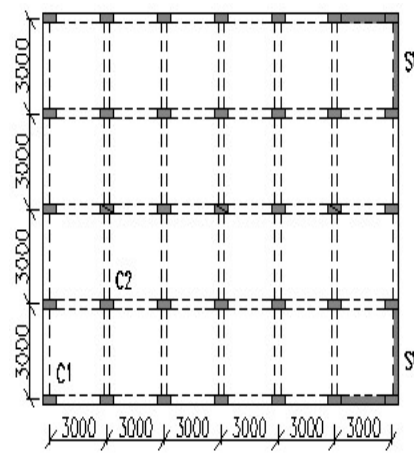

i) Model CM

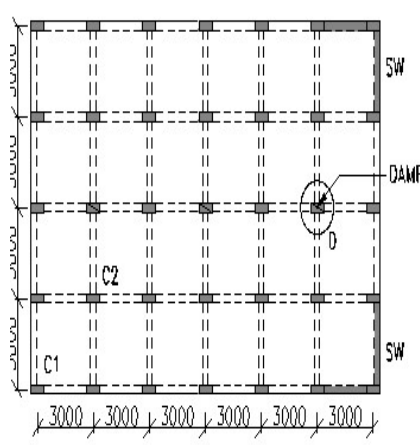

i) Model M2

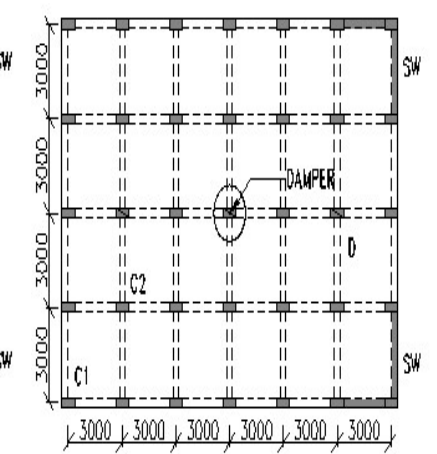

ii) Model M1

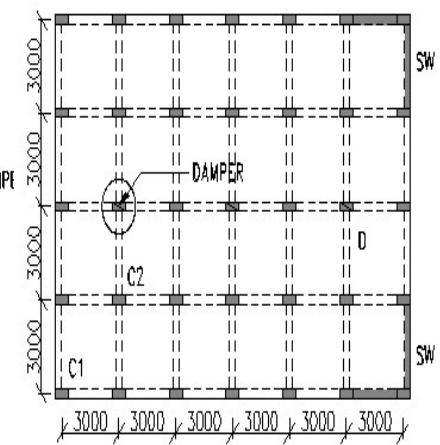

ii) Model M3
Fig -1: Building Models 
In all above model the mass ratio of pendulum damper is kept equal to 0.03 . The location of the damper is kept symmetrical in other direction. The building is subjected to Elcentro real time history record. The response of the building in both the principal direction is plotted with respect to the response parameters

\section{MODELING AND ANALYSIS}

The building is modeled using SAP analysis package. The beams and columns are modeled using two nodded line element with six degrees of freedom at each node. The slab is modeled using shell element. The building is modeled as base frame without considering the stiffness of infill wall. For modeling of pendulum damper the linear link element has been used for which the translational stiffness are calculated using mass of damper and time period.

Table -1: Data used for analysis

\begin{tabular}{|l|l|}
\hline Response reduction factor & 5 \\
Importance factor & 1.5 \\
Soil condition & Medium \\
Seismic Zone & V \\
Type of frame & SMRF \\
Plan size & $12 \times 18 \mathrm{~m}$ \\
External wall & $230 \mathrm{~mm}$ \\
Internal wall & $115 \mathrm{~mm}$ \\
Unit weight of Brick masonry & $18 \mathrm{KN} / \mathrm{m} 3$ \\
Unit weight of RC material & $25 \mathrm{KN} / \mathrm{m} 3$ \\
Thickness of slab & $150 \mathrm{~mm}$ \\
Thickness of shear wall & $200 \mathrm{~mm}$ \\
Floor to floor height & $3.2 \mathrm{~m}$ \\
Grade of steel & Fe 500 \\
Grade of concrete & $\mathrm{M} 35$ \\
Floor finish & $1.5 \mathrm{KN} / \mathrm{m} 2$ \\
Live load & $3.0 \mathrm{KN} / \mathrm{m} 2$ \\
Depth of foundation & $3.0 \mathrm{~m}$ \\
Height of parapet & $1 \mathrm{~m}$ \\
\hline
\end{tabular}

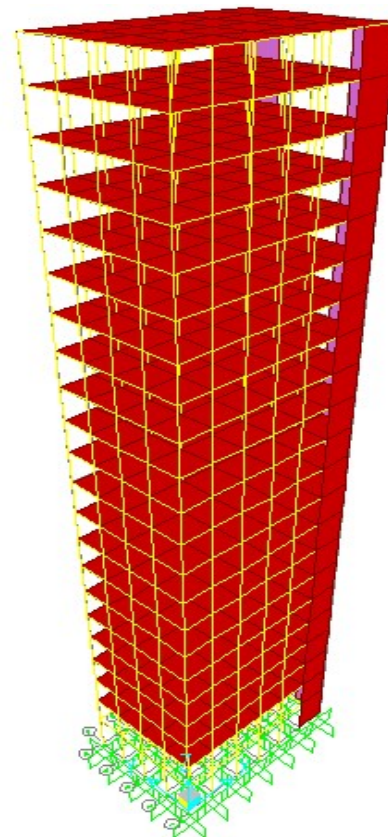

Fig -2: Mathematical Model

\section{RESULTS AND DISCUSSION}

\subsection{Modal Response}

The modal time period for all the models are presented in Fig. 3

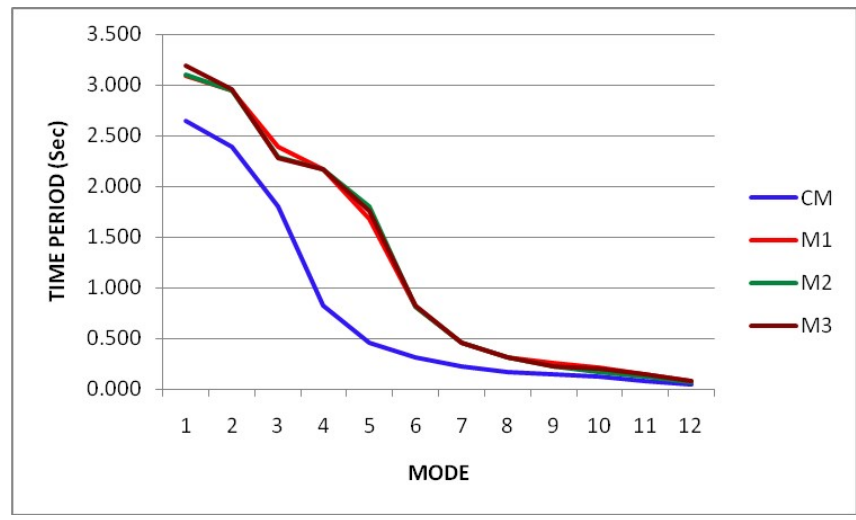

Fig -3: Modal Time period

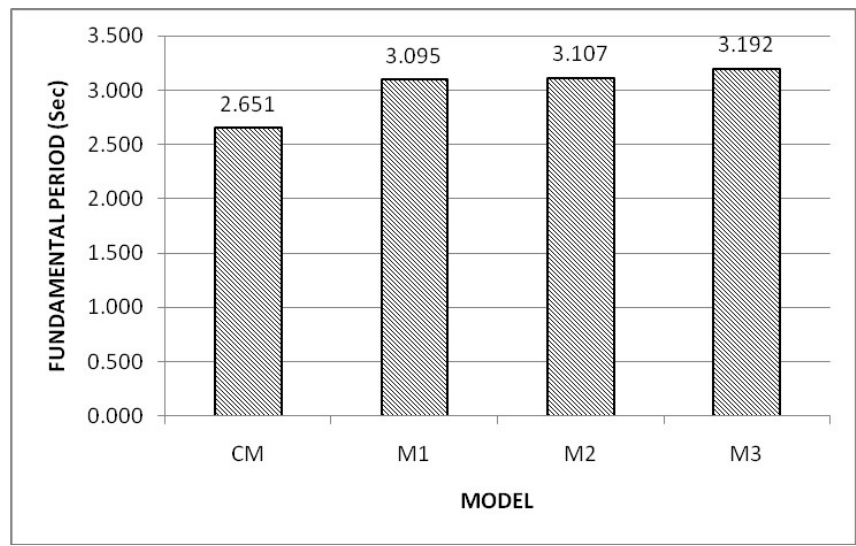

Fig -4: Modal Time period for Fundamental mode

The result obtained from the modal analysis shows that the modal time period for fundamental mode is found to be maximum for model M3. The modal deformation shape for mode 3 shows that there is good control over torsion for all the models compared to control model CM.

\subsection{Displacement and Base Shear}

The displacement and base shear time history for all the models are in both principal directions are shown in Fig- 5 to Fig-8

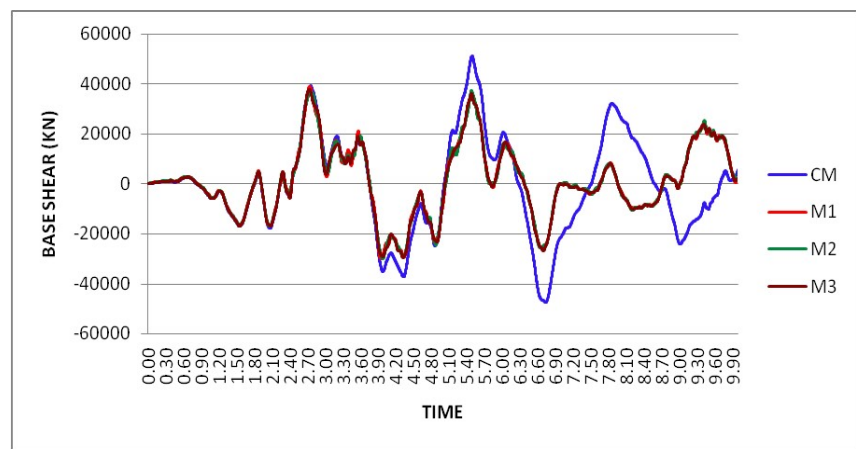

Fig -5: Time history of base shear Along X 


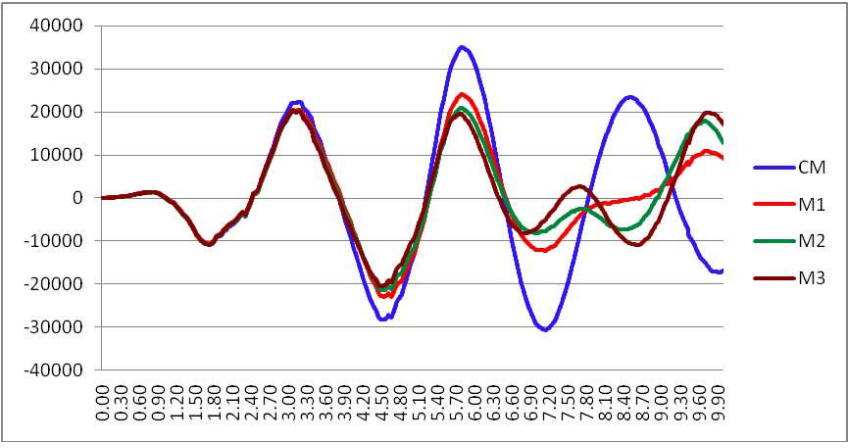

Fig -6: Time history of base shear Along y

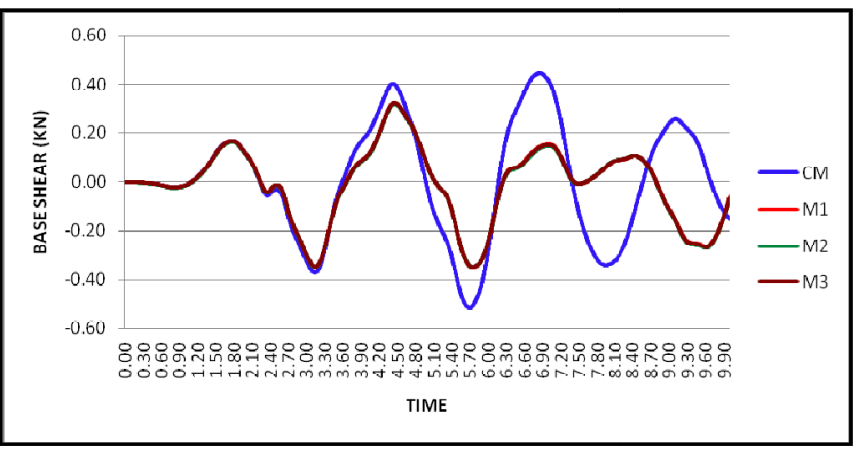

Fig -7: Time history of roof displacement along X

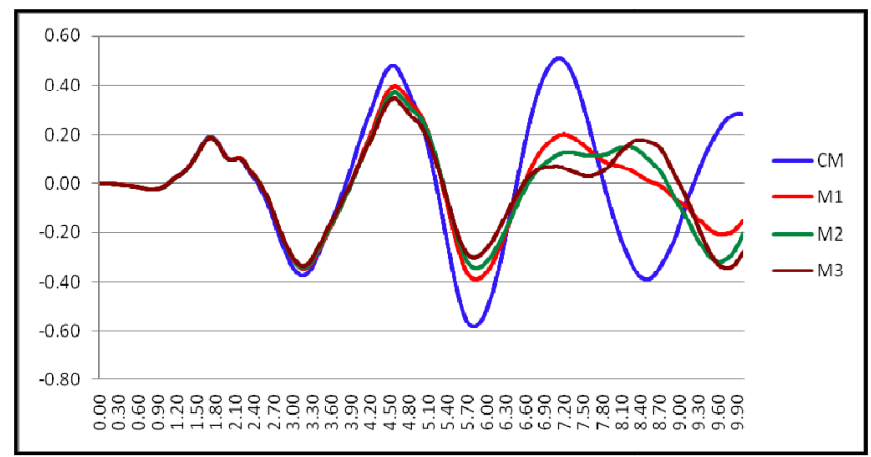

Fig -8: Time history of roof displacement along Y

The observation of displacement and base shear time history show that there is not much difference in displacement as well as base shear for different location of damper along the axis where the building is symmetrical. The response is found to be minimum for model M1 where the damper is symmetrically placed at the centroid of the building. The maximum base shear and displacement along both the directions are shown in Figure 9 to 12 below. The maximum displacement and base shear for model M1(Damper provided at centroid of building) is found to be minimum along $\mathrm{X}$ direction along which the building is symmetrical in stiffness. The displacement and base shear is minimum for model M3(Damper provided away from shear wall ie building stiffer side) where the building is Unsymmetrical in stiffness, however it should be noted that not much reduction in base shear and displacement was observed between model M1, M2 and M3. The base shear and displacement is found to be reduced as compared to model $\mathrm{CM}$ (Control model without damper). There is around 28 to $30 \%$ reduction in base shear and displacement was observed for the building with tuned mass dampers.

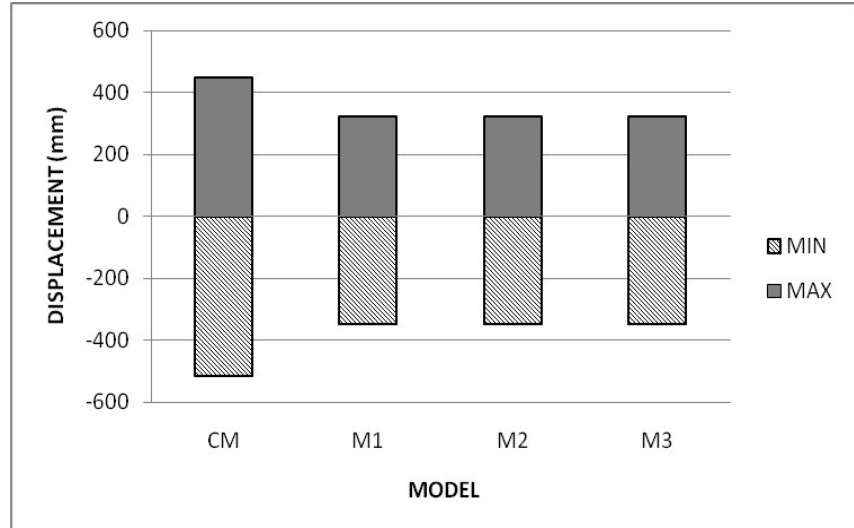

Fig -9: Maximum roof displacement along X

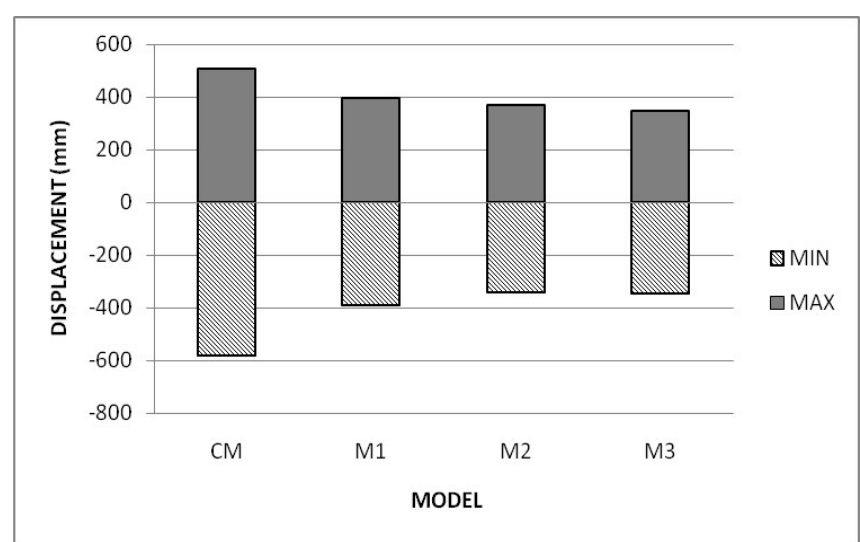

Fig -10: Maximum roof displacement along Y

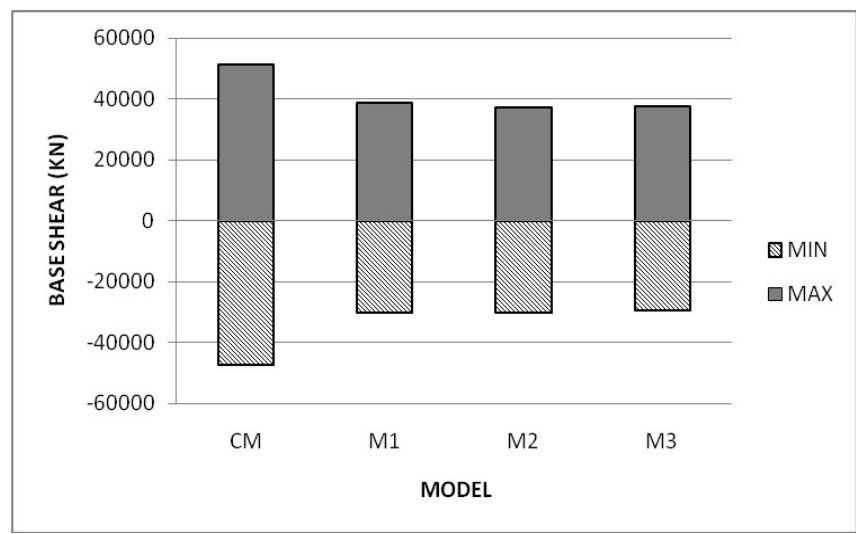

Fig -11: Maximum base shear along X

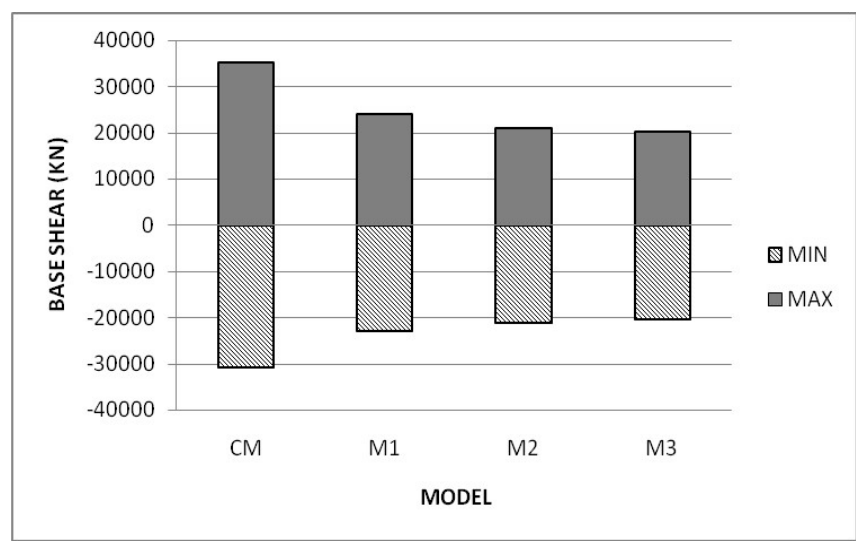

Fig -12: Maximum base shear along $\mathrm{Y}$ 


\subsection{Maximum Forces in Columns}

The observed the effect on maximum column forces two columns of the building is selected one is outer column and one is inner column. The maximum forces in columns are presented along both the principal directions.

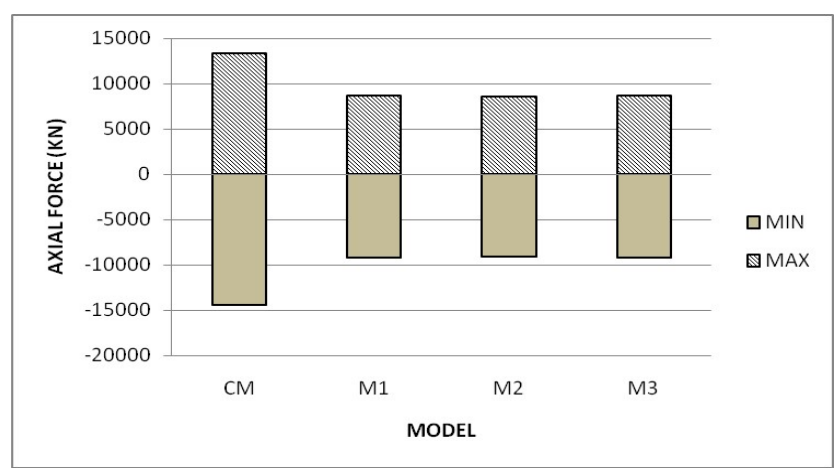

Fig -13: Max. Axial force in C1 Along X

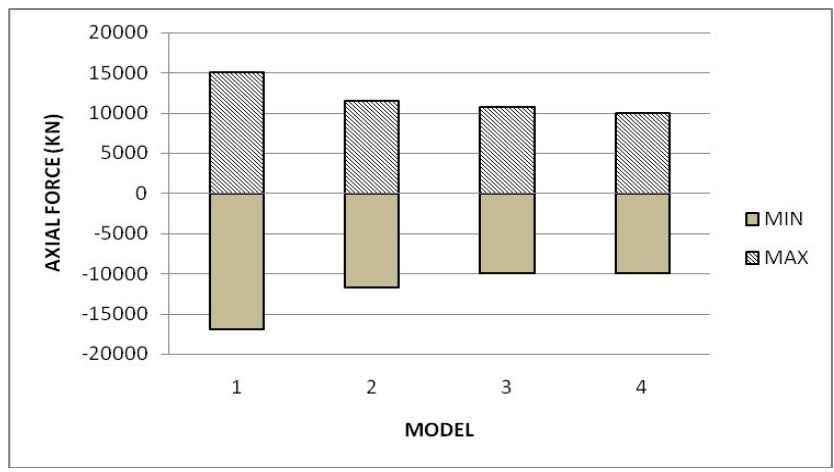

Fig -14: Max. Axial force in $\mathrm{C} 1$ Along $\mathrm{Y}$

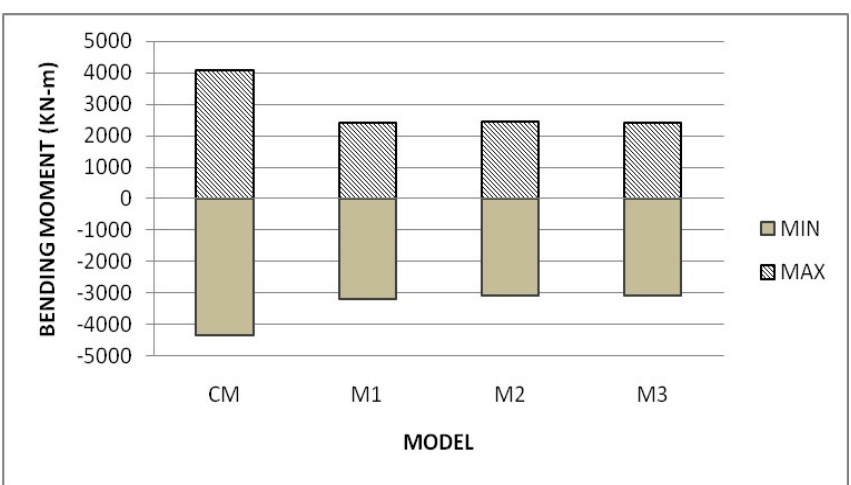

Fig -15: Max. Bending Moment in C1 Along X

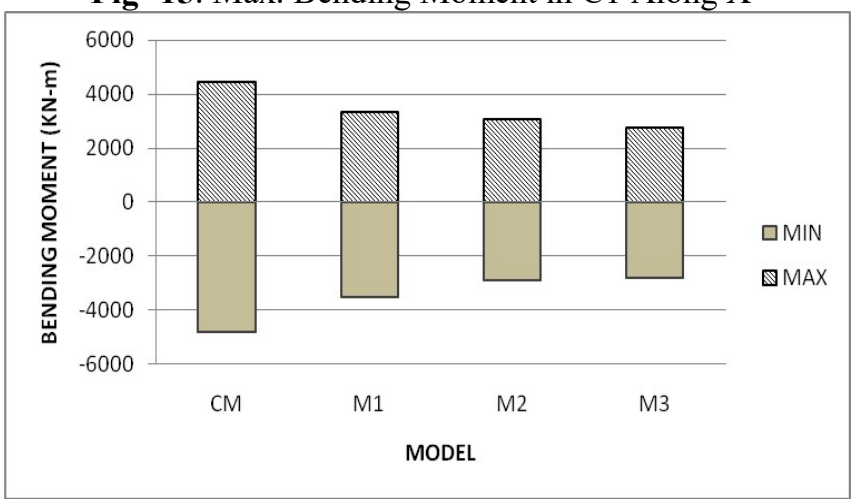

Fig -16: Max. Bending Moment in C1 Along Y

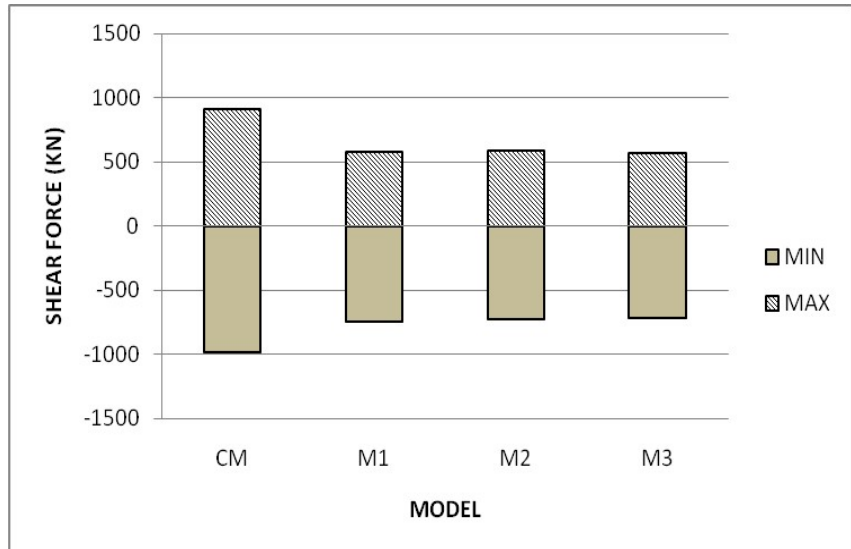

Fig -17: Max. Shear Force in C1 Along X

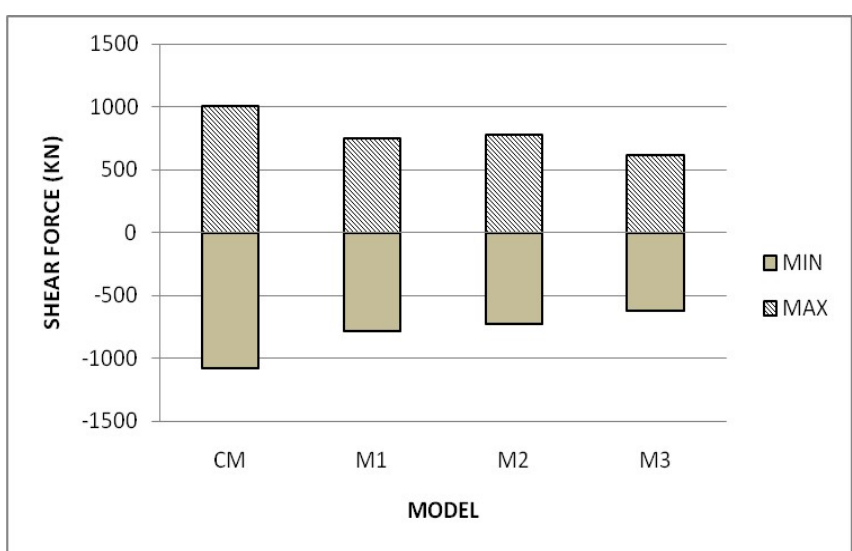

Fig -18: Max. Shear Force in C1 Along Y

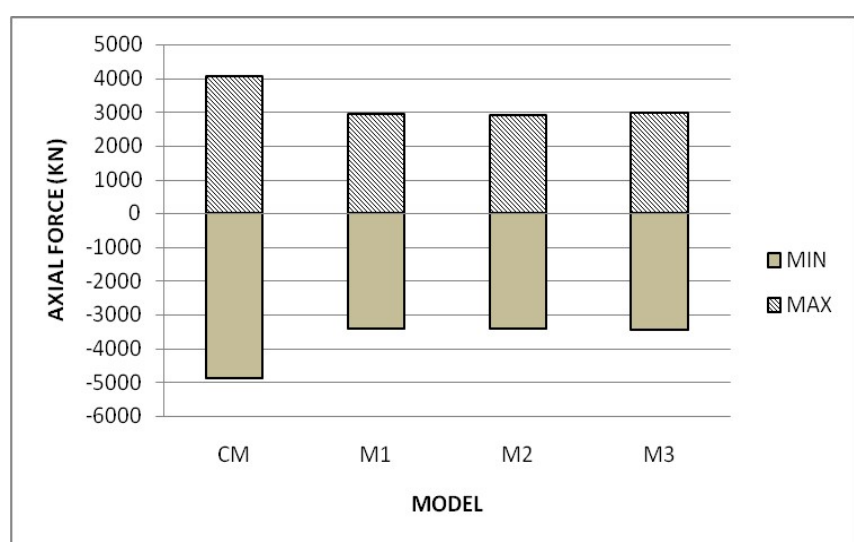

Fig -19: Max. Axial force in C2 Along $\mathrm{X}$

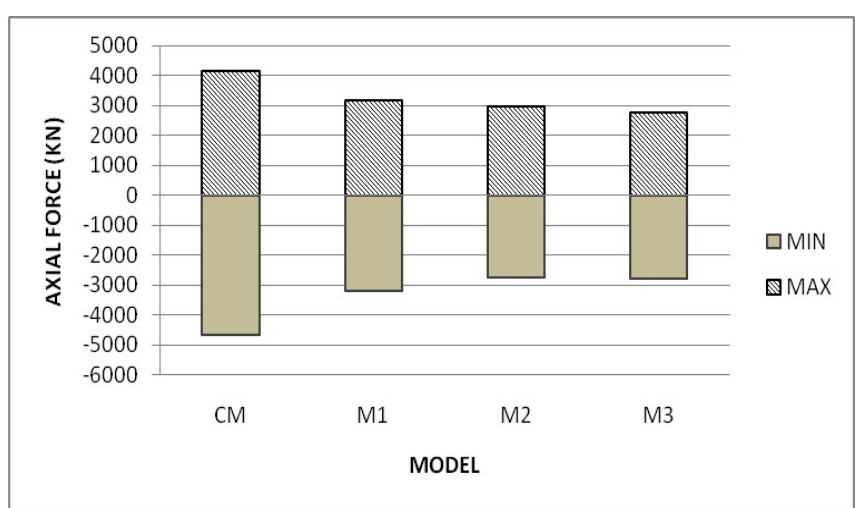

Fig -20: Max. Axial force in $\mathrm{C} 2$ Along $\mathrm{Y}$ 


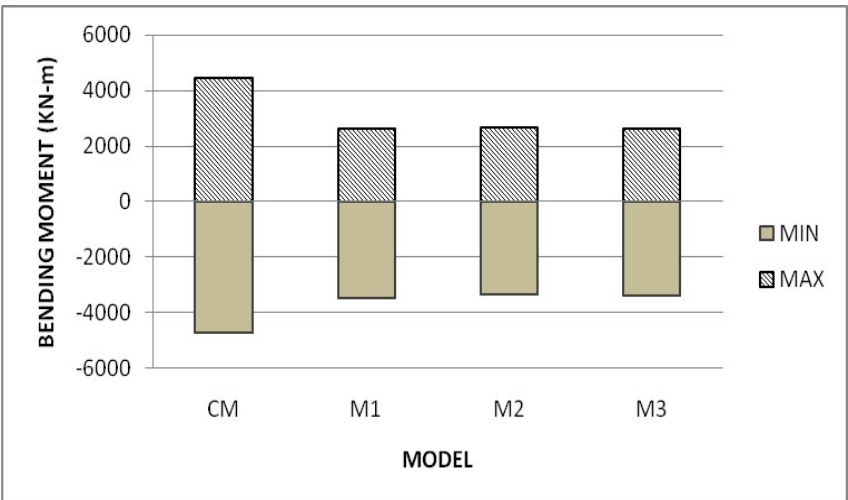

Fig -21: Max. Bending Moment in C2 Along X

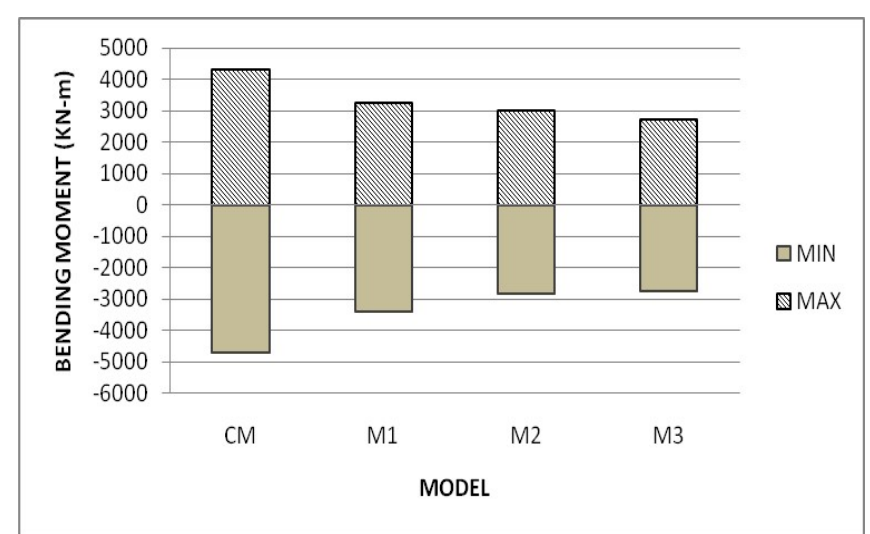

Fig -22: Max. Bending Moment in C2 Along Y

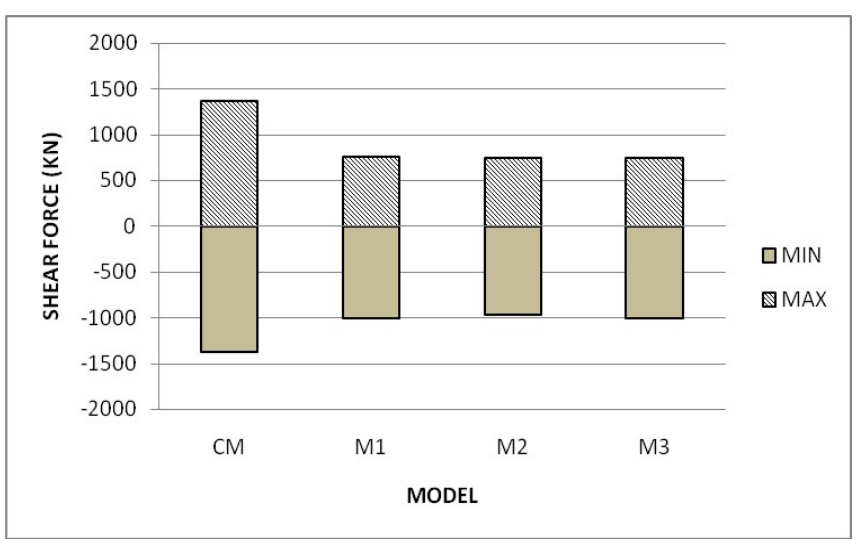

Fig -23: Max. Shear Force in C2 Along X

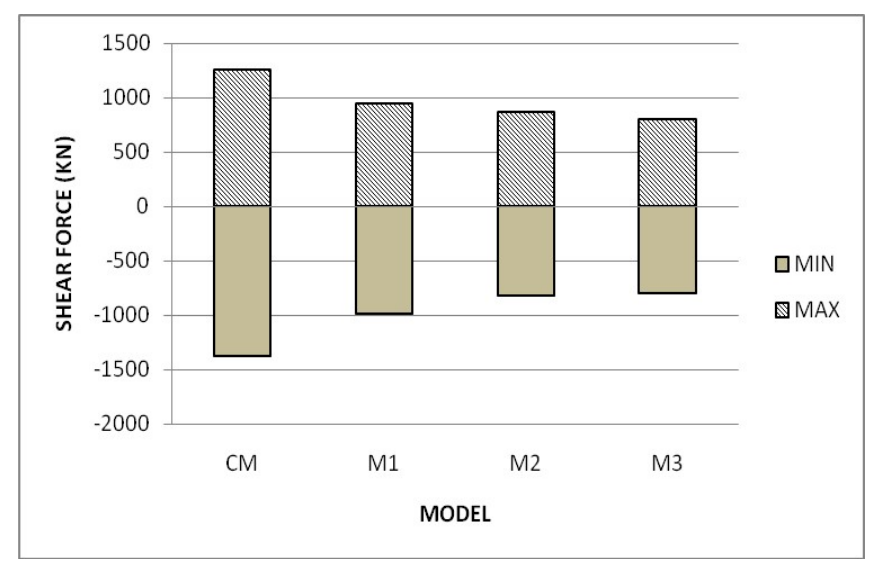

Fig -24: Max. Shear Force in C2 Along Y
The force in outer column is found to be minimum in model M1 (Dampers provided at centre of building) along $X$ direction ( Axis along which the building is symmetrical) where as in Y direction the model M3 (dampers located away from shear walls) has minimum forces. It can be stated from the results that the dampers should be located away from stiff walls to have a better control over the forces in that direction. There is around 33 to $38 \%$ reduction in axial force, shear force and bending moment was observed in Model M3 along Y direction compared to model CM. There is aroud 35 to $40 \%$ reduction in axial force, shear force and bending moment was observed along $\mathrm{X}$ direction in model M1 as compared to model CM.

\section{CONCLUSION}

The damper location is found to be crucial about an axis where the stiff element like shear wall is located unsymmetrically. Along the axis (X axis) in which the shear wall location is symmetrically located, the dampers provided at the centroid of building was observed to be an efficient location. There is around 35 to $40 \%$ reduction in axial force, shear force and bending moment was observed in Model M1 compared to model M3. Along the axis(Y axis) in which the shear wall is unsymmetrically located, the damper placed away from shear wall was observed to be an efficient location.Tthere is around 33 to $38 \%$ reduction in axial force, shear force and bending moment was observed in model M3 (dampers located away from shear wall) as compared to model CM. There is not much difference in maximum response quantities like displacement, base shear and forces by variation in damper location. From the results obtained it is recommended that the pendulum tuned mass dampers should be located away from the building stiff element like shear wall.

\section{REFERENCES}

[1] Davorin Hrovat, Finhas Barak, and Michael Rabins (1983), "Semi-active versus passive or active tuned mass dampers for structural control." Journal of Engineering Mechanics, Vol. 109, No. 3, June, 1983.

[2] Kenny C. S. Kwok (1984), "Damping increase in building with tuned mass damper." Journal of Engineering Mechanics, Vol. 110, No. 11, November, 1984.

[3] C. C. Chang and Henry T. Y. Yang (1995), "Control of buildings using active tuned mass dampers" Journal of Engineering Mechanics, Vol. 121, No.3, March, 1995.

[4] Hua-Jun Li and Sau-Lon James Hu, M.ASCE (2002), "Tuned Mass Damper Design for Optimally Minimizing Fatigue Damage" Journal of Engineering Mechanics, Vol. 128, No. 6, June 1, 2002.

[5] John R. Sladek and Richard E. Klingner (1983), "Effect of tuned-mass dampers on seismic response" Journal of Structural Engineering, Vol. 109, No. 8, August, 1983.

[6] Mehdi Setareh, Associate Member, ASCE, and Robert D. Hanson, Member, ASCE (1992), "Tuned mass dampers for balcony vibration control" Journal of Structural Engineering, Vol. 118, No. 3, March, 1992. 
[7] Genda Chen, Member, ASCE, and Jingning $\mathrm{Wu}$, Student Member, ASCE (2001), "Optimal placement of multiple tune mass dampers for seismic structures" Journal of Structural Engineering, Vol. 127, No. 9, September, 2001.

[8] Mehdi Setareh, M.ASCE, John K. Ritchey, Thomas M. Murray, M.ASCE, Jeong-Hoi Koo, and Mehdi Ahmadian (2007), "Semi active tuned mass damper for floor vibration control" Journal of Structural Engineering, Vol. 133, No. 2, February 1, 2007.

[9] Mehdi Setareh, M.ASCE, John K. Ritchey, Anthony J. Baxter, and Thomas M. Murray, F.ASCE (2006), "Pendulum Tuned Mass Dampers for Floor Vibration Control" Journal of Performance of Constructed Facilities, Vol. 20,No. 1, February 1, 2006.

\section{BIOGRAPHIES}

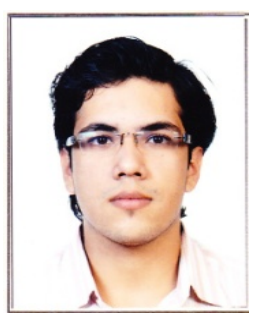

Prasad S. Kulkarni is a final year P.G. student of sapkal college of engineering nashik. He is graduated from university of pune in 2014 in distinction. He has presented a paper on "Effect of orientation and specific surface of reinforcement on compressive strength of ferrocement" in FS2013, pune.

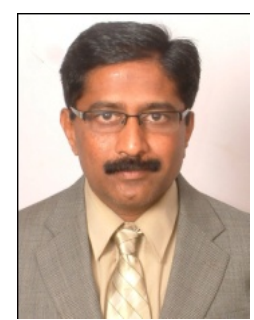

Prof. Dr. R. S. Talikoti is a Ph.D in Structural Engineering (IIT Bombay). He is working as a Professor and head of Civil engineering at Sapkal knowledge hub, Nashik. He has experience of teaching, R\&D, administration, and consultancy over two decades. He has published / presented 15+ research papers in reputed international and national journals/ conferences. 